\title{
The Augmentation Effect of N-Acetyl Cysteine Antioxidant on Superoxide Dismutase Levels in Schizophrenic Patients Treated with Risperidone
}

\author{
Vita Camellia*(D), Khairunnisa Khairunnisa ${ }^{1}$, Muhammad Ichwan ${ }^{3}$, Muhammad Surya Husada ${ }^{1}$, Elmeida Effendy ${ }^{1}$, \\ Rusdiana Rusdiana ${ }^{4}$, Deasy Hendriaty ${ }^{5}$ \\ ${ }^{1}$ Department of Psychiatry, Faculty of Medicine, Universitas Sumatera Utara, Medan, Indonesia; ${ }^{2}$ Department of Pharmacology, \\ Faculty of Pharmacy, Universitas Sumatera Utara, Medan, Indonesia; ${ }^{3}$ Department of Pharmacology, Faculty of Medicine, \\ Universitas Sumatera Utara, Medan, Indonesia; ${ }^{4}$ Department of Biochemistry, Faculty of Medicine, Universitas Sumatera \\ Utara, Medan, Indonesia; ${ }^{5}$ Department of Psychiatry, Faculty of Medicine, Universitas Sumatera Utara, Medan, Indonesia
}

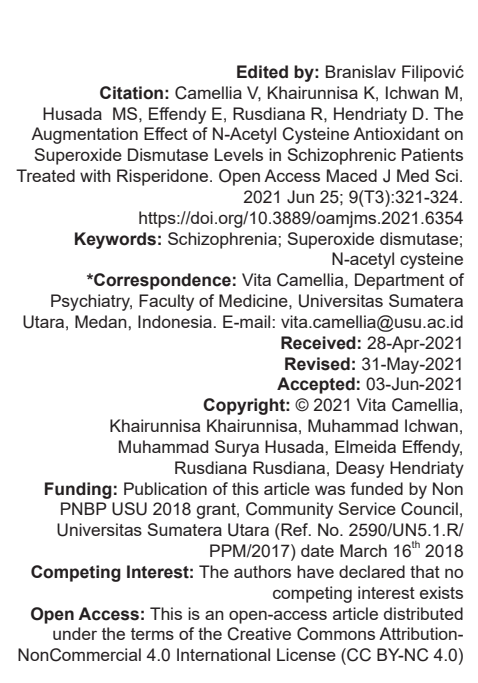

\section{Introduction}

Schizophrenia affects approximately $1 \%$ of the population and in Indonesia, the prevalence is around 400,000 people or as many as $1.7 / 1000$ population [1]. Schizophrenia is characterized by positive symptoms, negative symptoms, and also cognitive, aggressive, and affective symptoms [2], where negative symptoms reflect loss of function [3]. Negative symptoms are said to be associated with the alteration in central nervous system structure.

Many studies have examined the role of oxidative stress in pathogenesis, progression, and treatment of psychiatric disorders. One important factor that plays a role in the pathophysiology of schizophrenia is the excessive production of free radical substances and the failure of the anti-oxidant defense process [4]. CONCLUSION: $p=0.028$ research data show that NAC augmentation can improve the negative symptoms of schizophrenia through reducing SOD levels in the blood.

\section{Abstract} 列 $1.7 / 10,000$ individuals of the population. Schizophrenia is characterized by symptoms reflect loss of function. One important factor that plays a role in the pathophysiology of schizophrenia is

AIM: The aim of this study is to see how levels of superoxide dismutase change after $\mathrm{N}$-acetylcystein augmentation at each of the time points using Positive and Negative Syndrome Scale (PANSS), and SOD was measured in blood RESULTS: The average negative PANSS score in the Risperidone + NAC baseline group was $29.93( \pm 1.83)$; in statistically significantly different $(p=0.001)$ in the Risperidone + NAC group $(17.40 \pm 1.84)$ and in the risperidone

BACKGROUND: Schizophrenia affects approximately $1 \%$ of the population and in Indonesia, the prevalence is in schizophrenic patients treated with risperidone.

METHODS: This study is a pre-post experimental test design, where schizophrenic patients meet inclusion and the risperidon group $(21.00 \pm 0.74)$. The average baseline superoxide dismutase $(S O D)$ levels in the Risperidone + NAC group group was 8.15 (19.54) and $\triangle S O D$ in the risperidone group was $42.48 \pm(54.30)$.
\end{abstract}

The 2008 Uma et al. study showed that malondialdehyde level was increased in schizophrenia with positive symptoms (163\%), negative (137\%), and cognitive symptoms (132\%) compared to the control group. Free radicals, especially reactive oxygen species (ROS), superoxide, and highly reactive hydroxyl radicals have unpaired electrons in molecular or atomic orbits that are arranged in the center and directed under physiological conditions during aerobic metabolism. As hazardous free radicals, they are usually deactivated or sought for antioxidants before causing damage to lipids, proteins, or nucleic acids. Normally ROS is neutralized by an antioxidant defense mechanism, namely superoxide dismutase catalase and glutathione peroxidase, it is the primary enzyme involved in the direct disposal of ROS. Glutathione transferase, glucose-6-phosphate dehydrogenase, and copper-binding ceruloplasmin are secondary anti-oxidant enzymes that maintain a stable concentration of glutathione and NADPH for optimal function of the primary antioxidant 
enzymes [5]. Superoxide dismutase is an important enzyme that is important in detoxification from superoxide radicals because they are the first substances produced in the majority of reactions that resulted in biological free radicals. Several studies have shown that superoxide dismutase (SOD) levels are increase in patients with chronic schizophrenia. A study with 68 schizophrenic patients (29 males and 39 females), aged between 18 years old and 61 years old (group divided by age $<34$ years old, and $>34$ years old) showed that SOD levels in patients with the age group below 34 years were significantly higher than in the older group of patients [6]. Several studies have shown that administration of N-Acetyl Cysteine (NAC) can improve the enhancement of negative symptoms in schizophrenic patients [7]. NAC is a derivative of the amino acid L-cysteine and is rapidly absorbed orally. NAC can modulate several dopamine and glutamate neurotransmission systems. In the pathophysiology of schizophrenia, there is a decrease in glutamate levels in the prefrontal cortex and dysfunction in glutamate metabolism. Oxidative stress is also linked to the severity of symptoms, subtypes of schizophrenia, and oxidative stress [8].

Based on the results of previous studies, this research aims to see how much changes of the level of the enzyme SOD in the serum of schizophrenic patients treated with risperidone who received additional NAC and who only received risperidone treatment.

\section{Methods}

This study is a pre- and post-test design experimental study, in which 27 samples were patients in the Mental Institution "RS Jiwa Provinsi Sumatera Utara" that met the inclusion criteria, who had been diagnosed according to ICD-10 to rule out other mental problems. Subjects have gone through structured interviews using MINI ICD-10 to evaluate the severity of negative symptoms. Patients were examined with a Positive and Negative Syndrome Scale (PANSS)-Negative scale where all subjects have a score $\geq 21$. All schizophrenic patients received risperidone $4 \mathrm{mg} /$ day in the stabilization phase. Exclusion criteria were subjects who had organic mental disorders and had a history of common medical conditions, especially hypertension, stroke, diabetes mellitus, cholesterol, and infectious diseases. The 27 samples are divided into 2 groups according to age, number of cigarettes, body mass index (BMI), and duration of illness and the severity levels measured by PANSS. Group one comprised 15 individuals and group two comprised 12 individuals. Group one was the group that received additional NAC, NAC was given at baseline of $1000 \mathrm{mg} /$ day, and increased in week 2 up to $2000 \mathrm{mg} /$ day and was maintained until week 8 . SOD levels were measured at baseline and in week 8 , and compared with group 2 that only received risperidone $4 \mathrm{mg} /$ day.
Superoxide dismutase serum was measured by ELISA method, using the Human Super Oxidase Dismutase kit (Bioassay Technology Laboratory) in accordance with the factory protocol [9].

\section{Results}

In Table 1, it shows the average age of the sample is 36.25 ( \pm 6.76$)$; with an average duration of illness $5.3( \pm 1.75)$ years, with an average BMI was 21, 24 (1.82), the average positive-PANSS score was $11.11( \pm 2.22)$; negative-PANSS score was 30.02 $( \pm 1.66)$, average general psychopathology-PANSS score was $31.05( \pm 3.72)$, and an average total-PANSS score was $72.16( \pm 5.74)$. Average SOD score was 88 , $79( \pm 132.31)$ with level ranges from 0.00 to 574 .

Table1: Demographic characteristic of research subject

\begin{tabular}{llll}
\hline Variable & Risperidone + NAC $(\mathrm{n}=15)$ & Risperidone $(\mathrm{n}=12)$ & $\mathrm{p}$ \\
\hline Age & $35.27(6.34)$ & $38.58(7.86)$ & $0.34^{\mathrm{a}}$ \\
Education & & & \\
$\quad$ Junior high school $\mathrm{n}(\%)$ & $5(33.33)$ & $6(50)$ & \\
$\quad$ Public high school $\mathrm{n}(\%)$ & $10(66.67)$ & $6(50)$ & \\
Marital status & & & \\
$\quad$ Married $\mathrm{n}(\%)$ & $7(46.67)$ & $6(50)$ & \\
$\quad$ Not married $\mathrm{n}(\%)$ & $8(53.33)$ & $6(50)$ & $0.59^{\mathrm{b}}$ \\
Duration of illness & $4.73(1.49)$ & $6.17(1.99)$ & $0.18^{\mathrm{b}}$ \\
Smoking & $2.07(1.49)$ & $2.83(1.53)$ & $0.13^{\mathrm{a}}$ \\
BMl & $21.02(1.74)$ & $22.06(1.72)$ & \\
Dose & NAC 2000 mg/day + & Risperidone 4 mg & \\
& Risperidone 4 mg & & \\
\hline${ }^{\mathrm{a}}$ t-test ${ }^{\mathrm{b}}$ Mann-Whitney U. & & &
\end{tabular}

Table 2 shows the mean of positive-PANSS score in \pm the group receiving risperidone with NAC was $10.80( \pm 2.34)$, in risperidone group was 11.58 $( \pm 2.19)$ at baseline. After 8 weeks, the mean score was $7.93( \pm 1.28)$ at the risperidone with NAC group and $7.17( \pm 0.58)$ in risperidone group. The negativePANSS scale score at the baseline was $29.93( \pm 1.83)$ in risperidone with NAC group and $29.83( \pm 1.19)$ in risperidone group at the baseline. After week 8 , it was found at $17.40( \pm 1.84)$ risperidone with NAC group, $21.00( \pm 0.74)$ in risperidone group. In general, psychopathology PANSS score at baseline was 31.33 $( \pm 3.66)$ in risperidone with NAC group and $29.92( \pm 3.78)$ in risperidone group. After 8 weeks, it was found 22.73 $( \pm 3.56)$ in risperidone with NAC group and $23.58( \pm 3.23)$ in risperidone group. The total PANSS score at baseline, $71.80( \pm 6.13)$ in risperidone with NAC group and 71.33 $( \pm 5.76)$ in risperidone group. After 8 weeks, it was found $48.07( \pm 4.96)$ in risperidone with NAC group, 52.67 $( \pm 5.16)$ in risperidone group.

In Table 3, while SOD scores did vary at baseline between the group receiving NAC and the group not receiving NAC, there was a substantial change in SOD levels observed after 8 weeks with a delta of 42 Units / $L$ in the group without receiving SOD compared to a delta of only $8 \mathrm{U} / \mathrm{L}$ in the group receiving the addition of NAC 
Table 2: PANSS score

\begin{tabular}{|c|c|c|c|}
\hline & $\begin{array}{l}\text { Risperidone + } \\
\text { NAC (mean SD) }\end{array}$ & Risperidone & $p$ \\
\hline \multicolumn{4}{|c|}{ PANSS positive scale score } \\
\hline Baseline & $10.80(2.34)$ & $11.58(2.19)$ & $0.38^{\mathrm{a}}$ \\
\hline Week 8 & $7.93(1.28)$ & $7.17(0.58)$ & $0.15^{\mathrm{b}}$ \\
\hline \multicolumn{4}{|c|}{ PANSS negative scale score } \\
\hline Baseline & $29.93(1.83)$ & 29.83(1.19) & 0.87 \\
\hline Week 8 & $17.40(1.84)$ & $21.00(0.74)$ & $0.001^{\mathrm{a}}$ \\
\hline \multicolumn{4}{|c|}{ PANSS general psychopathology scale score } \\
\hline Baseline & $31.33(3.66)$ & 29.92(3.78) & $0.33^{\mathrm{a}}$ \\
\hline Week 8 & $22.73(3.56)$ & 23.58(3.23) & 0.53 \\
\hline \multicolumn{4}{|c|}{ Total PANSS score } \\
\hline Baseline & $71.80(6.13)$ & $71.33(5.76)$ & $0.54^{\mathrm{a}}$ \\
\hline Week 8 & $48.07(4.96)$ & $52.67(5.16)$ & $0.03^{\mathrm{a}}$ \\
\hline
\end{tabular}

In Table 4, it shows the delta SOD level in the risperidone administration added with NAC is 8.15 (19.54), while the one who only received risperidone was 42.48 (54.30).

Table 3: Level of SOD(U/L) in serum

\begin{tabular}{llll}
\hline Levels of SOD(U/l): & Risperidone + NAC & Risperidone & $\mathrm{p}$ \\
\hline Baseline & $63.57(22.44)$ & $85.79(101.05)$ & $<0.05$ \\
Week 8 & $71.72(31.20)$ & $128.27(117.67)$ & \\
\hline
\end{tabular}

\section{Discussion}

This study shows that NAC augmentation in schizophrenic patients treated with risperidone can reduce the level of SOD increase. NAC is able to reduce the level of free radicals in the blood in schizophrenic patients. According to Berk et al., NAC is a precursor of glutathione which has a neurotropic antioxidant effect and has a modulation effect on dopaminergic and glutamatergic systems. Along with this study, it was shown that there is a negative symptom improvement in the group receiving NAC [8]. According to Farokhnia et al., NAC shows an effective and safe augmentation strategy, reducing negative symptoms in schizophrenic patients [7].

Table 4: Changes in level of SOD(U/L) in serum

\begin{tabular}{llll}
\hline $\mathrm{SOD}(\mathrm{U} / \mathrm{l})$ & Risperidone+NAC & Risperidone & $\mathrm{p}$ \\
\hline$\Delta \mathrm{SOD}$ & $8.15(19.54)$ & $42.48(54.30)$ & $0.028^{\mathrm{b}}$ \\
\hline${ }^{\mathrm{D}}$ Mann-Whitney U. & & &
\end{tabular}

A double-blind placebo-controlled trial adding 1000 mg/day NAC for 6 months in 140 participants shows a decrease in negative symptoms. According to Pazvantoglu et al., the severity of symptoms may correspond to antioxidant levels. Various antioxidants are linked to negative symptoms, poor premorbid function, and abnormalities of computed tomography (CT) [10]. However, there is no correlation between the duration of the disease and the levels of antioxidants found. Gunnes et al. state that oxidative stress is higher in schizophrenic patients than controls in which an increase in negative symptom severity coincided with damage to oxidative balance [4]. Oxidative stress was lower in patients using atypical antipsychotics than the one with typical antipsychotics and antipsychotics combination. This suggests that the mechanism of atypical antipsychotics has a positive effect on oxidative stress, thus it indicates improvement in negative symptoms better than typical.

This study shows that the administration of single risperidone continues to increase the SOD levels, which shows that oxidative stress continues to increase during risperidone administration. NAC is a candidate drug that may be suggested in the administration of atypical antipsychotics to reduce the increase in oxidative stress.

The strength of this study is that it has controlled the duration of illness, BMI, smoking status, age, gender, severity of negative symptoms before administration of NAC, and measurement of SOD level. However, the limitation of this study is that the number of samples is quite limited. Further research is needed to examine SOD levels in schizophrenic patients with long-term treatment or stable phases.

\section{Conclusions}

NAC is able to improve negative symptoms, most likely through alleviating oxidative stress in schizophrenic patients treated with risperidone. Therefore, NAC is a potential augmentation therapy in schizophrenia with negative symptoms.

\section{Declarations}

\section{Authors' contributions}

All authors contributed to the study and writing of the article. All authors have read and approved the final version of the manuscript. $\mathrm{DH}$ and EE contribute in finding sample for this study, VC and $\mathrm{MSH}$ contribute in monitoring the clinical conditions of the sample, $\mathrm{Ml}$ and $\mathrm{K}$ contribute in medicine preparation and making sure the sample took medicine every day, $\mathrm{R}$ contribute in measuring the level of SOD serum.

\section{Acknowledgments}

The authors wish to thank the Mental Institution "RS Jiwa Propinsi Sumatera Utara" for supporting this study.

\section{Ethics approval and consent to participate}

Written informed consent was obtained from all participants. This study was approved by ethic committee of Medical Faculty of Universitas Sumatera Utara. 


\section{References}

1. Ministry of Health of Republic Indonesia: Riset Kesehatan Dasarl; 2013. [Last accessed on 2021 May 12]. Available from: https://www.depkes.go.id.

2. Chomczynski P, Sacchi N. Single-step method of RNA isolation by acid guanidinium thiocyanate-phenol-chloroform extraction. Anal Biochem. 1987;162(1):156-9. https://doi. org/10.1016/0003-2697(87)90021-2

\section{PMid:2440339}

3. Remington G, Foussias G, Fervahana G, Agid O, Takeuchi H, Lee J, et al. Treating negative symptoms in schizophrenia: An update. Curr Treat Options Psychiatry 2016;3:133-50. https:// doi.org/10.1007/s40501-016-0075-8 PMid:27376016

4. Gunes M, Altindag A, Bulut M, Demir S, Ibiloglu A, Kaya M, et al Oxidative metabolism may be associated with negative symptoms in schizophrenia. Psychiatry Clin Psycopharmacol. 2017;27(1):54-61. https://doi.org/10.1080/24750573.2017.1293243

5. Uma D, Chinnaswamy P. Oxidative injury and enzymic antioxidant misbalance in schizophrenics with positive, negative and cognitive symptoms. Afr J Biochem Res. 2008;2(4):92-7.
6. Djordjevic V, Lazarevis D, Cosic V, Knezevic M, Djordjevic V. Age-related changes of superoxide dismutase activity in patients with schizophrenia. Vojnosanit Pregl. 2017;74(1):31-7. https://doi.org/10.2298/vsp141202142d

7. Farokhnia M, Azarkolah A, Adinehfar F, Khodaiae-arkadani M, Hosseini S, Yekehtaz $\mathrm{H}$, et al. $\mathrm{N}$-acetylcisteine as an adjunct to risperidone for treatment of negative symptoms in patients with chronicschizophrenia. Clin Neuropharmacol. 2013;36(6):185-92. https://doi.org/10.1097/wnf.0000000000000001

PMid:24201233

8. Berk M, Malhi G, Gray L, Dean O. The promise of n-acetylcysteine in neuropsychiatry. Trends Pharmacol Sci. 2013;34(3):167-77. https://doi.org/10.1016/j.tips.2013.01.001 PMid:23369637

9. Bioassay Technology Laboratory, Human Superoxidase Dismutase ELISA. [Last accessed on 2021 May 12]. Available from: https://www.bt-laboratory.com.

10. Pazvantoglu O, Selek S, Okay T, Sengul C, Koray K Dilbaz $\mathrm{N}$, et al. Oxidative mechanisms in schizophrenia and their relationship with illness subtype and symptom profile. Psychiatry Clin Neurosci. 2009;63(5):693-700. https://doi. org/10.1111/j.1440-1819.2009.02015.x

PMid:19788631 